\title{
Polymeric Thermal Microactuator With Embedded Silicon Skeleton: Part II-Fabrication, Characterization, and Application for 2-DOF Microgripper
}

\author{
Trinh Chu Duc, Gih-Keong Lau, and Pasqualina M. Sarro, Fellow, IEEE
}

\begin{abstract}
This paper presents the fabrication, characterization, and application of a novel silicon-polymer laterally stacked electrothermal microactuator. The actuator consists of a deep silicon skeleton structure with a thin-film aluminum heater on top and filled polymer in the trenches among the vertical silicon parts. The fabrication is based on deep reactive ion etching, aluminum sputtering, SU8 filling, and KOH etching. The actuator is $360 \mu \mathrm{m}$ long, $125 \mu \mathrm{m}$ wide, and $30 \mu \mathrm{m}$ thick. It generates a large in-plane forward motion up to $9 \mu \mathrm{m}$ at a driving voltage of $2.5 \mathrm{~V}$ using low power consumption and low operating temperature. A novel 2-D microgripper based on four such forward actuators is introduced. The microgripper jaws can be moved along both the $x$ - and $y$-axes up to 17 and $11 \mu \mathrm{m}$, respectively. The microgripper can grasp a microobject with a diameter from 6 to $40 \mu \mathrm{m}$. In addition, the proposed design is suitable for rotation of the clamped object both clockwise and counterclockwise.

[2007-0192]
\end{abstract}

Index Terms-Electrothermal microactuator, polymeric microactuator, SU8, 2-D microgripper.

\section{INTRODUCTION}

$\mathbf{P}$ OLYMERIC electrothermal actuators are of great interest in microelectromechanical systems technology as they are capable of producing large displacements at a low driving voltage and operating temperature [1]-[3]. Furthermore, the polymeric electrothermal actuators are capable of operating in liquid and can be biocompatible. However, most of the developed

Manuscript received July 31, 2007; revised January 10, 2008. First published June 13, 2008; last published August 1, 2008 (projected). Subject Editor S. M. Spearing.

T. Chu Duc was with the Electronic Components, Technology and Materials Laboratory, Delft Institute of Microsystems and Nanoelectronics, Delft University of Technology, 2624 CT Delft, The Netherlands. He is now with the Faculty of Electronics and Telecommunication, College of Technology, Vietnam National University, Hanoi, Vietnam (e-mail: trinhcd@ coltech.vnu.vn).

G.-K. Lau was with the Department of Precision and Microsystems Engineering, Delft University of Technology, 2628 CD Delft, The Netherlands. He is now with the School of Mechanical and Aerospace Engineering, Nanyang Technological University, Singapore 639798 (e-mail: mgklau@ntu.edu.sg).

P. M. Sarro is with the Electronic Components, Technology and Materials Laboratory, Delft Institute of Microsystems and Nanoelectronics, Delft University of Technology, 2628 CT Delft, The Netherlands (e-mail: p.m.sarro@tudelft.nl).

Color versions of one or more of the figures in this paper are available online at http://ieeexplore.ieee.org.

Digital Object Identifier 10.1109/JMEMS.2008.924275 polymeric electrothermal microactuators employ two-material structures. The metal heater is deposited on the top of a high coefficient of thermal expansion (CTE) polymer layer. The structures are bent when heated. The interface between the heat source and the polymer layer is rather limited by the surface area of the metal layer, and the heat transfer along the vertical dimension is not effective. Since the polymer layers have low thermal conductivity, the reported structures [1], [2] have limited movement. Moreover, the unintended vertical movement couples and interferes with the desired lateral movement [1], [2].

We propose a novel silicon-polymer laterally stacked electrothermal in-plane forward microactuator. The device is composed of three materials: a metal heating layer, a silicon structure as frame with high heat conductivity, and a polymer with a high CTE. The design and modeling of the actuator is described in detail in a companion paper [4]. During actuation, heat is efficiently transferred from the heater to the polymer by employing the high thermal conduction of the deep silicon skeleton structure that provides a large interface with the surrounding polymer. Moreover, the polymer layer is constrained between two silicon plates. The thermal expansion of the constrained polymer is significantly larger than the no constraint one [4]-[6].

A very interesting application that largely benefits from the specific characteristics of these actuators is a novel 2-D silicon-polymer electrothermal microgripper. The development of microgrippers with large motion capability and low working temperature has become a great technological challenge for advanced microassembly, micromanipulation, and microrobotics. Conventional microgrippers or pipettes are used to manipulate microparticles [7]. However, the developed microgrippers and pipettes cannot be used to rotate individual microparticles, a function which is highly desirable during microassembly or micromanipulation [3], [8]. The microgripper introduced here is based on four forward silicon-polymer electrothermal actuators. The actuator device is capable of providing displacement in two dimensions in a plane that is generally parallel to the surface of the substrate. Besides the regular grasping operation of conventional microgrippers, this proposed 2-D microgripper is suitable for rotation of the clamped object. The device is made on silicon-on-insulator (SOI) silicon wafers with a CMOS-compatible fabrication process. 

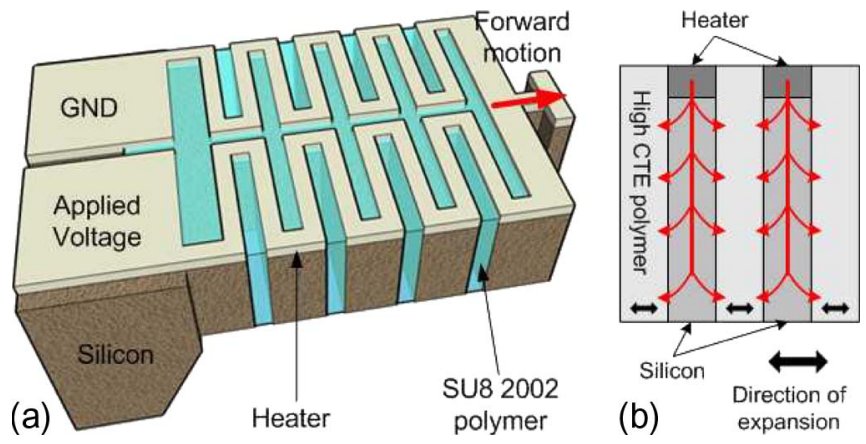

Fig. 1. (a) Schematic drawing of the silicon-polymer laterally stacked forward actuator. The vertically constrained polymer layers expand laterally when they receive heat transferred from the heater through the silicon meandering structure. (b) Heat transfer path (red line) and direction of expansion of the laterally constrained polymer layers.

\section{Frontside view}

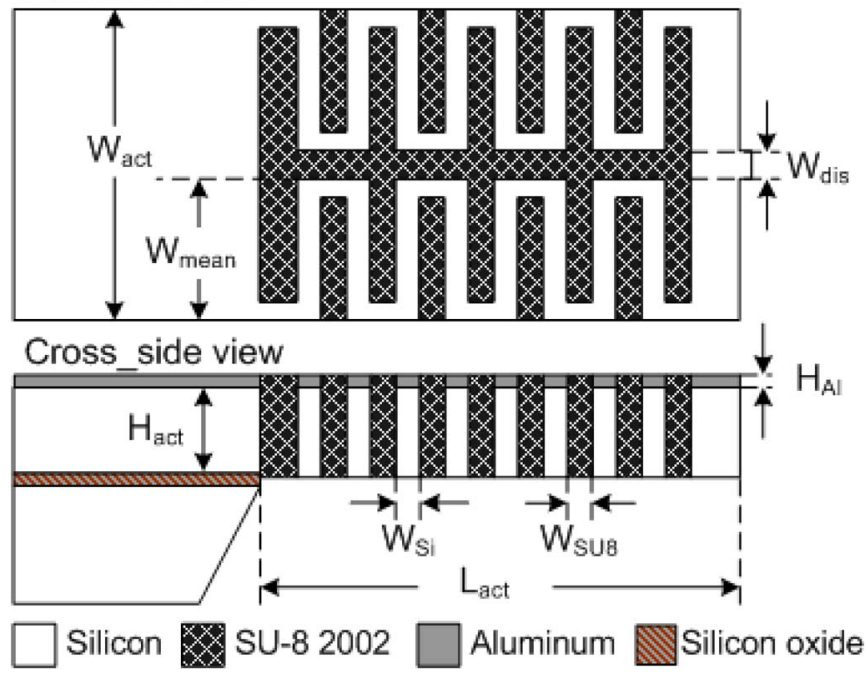

Fig. 2. Geometric parameters of the forward actuator.

\section{DESIGN}

The specific configuration of the device is based on the modeling results presented in [4]. A schematic drawing of the silicon-polymer electrothermal forward actuator is shown in Fig. 1(a). The device is based on a three-material composite. An aluminum metal heater is deposited and patterned on top of the silicon skeleton structure. The silicon part forms the frame structure and acts as a heat-conducting environment due to its high thermal conductivity. The polymer, which is an SU8 type, is embedded between the silicon parallel plates.

When a current is applied to the heater, the generated heat is efficiently transferred to the surrounding polymer through the deep meandering silicon structure that has a large interface with the polymer [see Fig. 1(b)]. The polymer layers expand along the lateral direction due to the constraint effect [4]-[6], causing forward displacement of the actuator. The actuation requires low driving voltage, power consumption, and operating temperature.

In Fig. 2, the geometry of the actuator is shown. The actuator is $360 \mu \mathrm{m}$ long, $125 \mu \mathrm{m}$ wide, and $30 \mu \mathrm{m}$ thick. It consists of two symmetrical silicon-polymer stacks. There are 40 vertical polymer layers in a stack. Each polymer and silicon platelike is
TABLE I

GEOMETRY OF THE ElECTROTHERMAL ForWARD ACTUATOR

\begin{tabular}{l|l|r|r}
\hline Parameters & Symbol & Value & Unit \\
\hline Silicon vertical plate width & $W_{S i}$ & 3 & $\mu \mathrm{m}$ \\
Silicon meandering width & $W_{\text {mean }}$ & 60 & $\mu \mathrm{m}$ \\
Actuator high & $H_{\text {act }}$ & 30 & $\mu \mathrm{m}$ \\
Actuator width & $W_{\text {act }}$ & 125 & $\mu \mathrm{m}$ \\
Actuator length & $L_{a c t}$ & 260 & $\mu \mathrm{m}$ \\
Aluminum thickness & $H_{A l}$ & 600 & $\mathrm{~nm}$ \\
SU8 layer width & $W_{S U 8}$ & 3 & $\mu \mathrm{m}$ \\
Distance between two meandering structures & $W_{\text {dis }}$ & 5 & $\mu \mathrm{m}$ \\
\hline
\end{tabular}

$3 \mu \mathrm{m}$ wide, $60 \mu \mathrm{m}$ long, and $30 \mu \mathrm{m}$ deep. The other parameters are shown in Table I. The ratios between the width of the polymer layer and the length and height of its bonded surface are 20 and 10, respectively. These values, which are larger or equal to ten, do satisfy the prerequisite for the maximum constrain effect [4]-[6]. According to the modeling, the expected displacement of this forward actuator is $8.1 \mu \mathrm{m}$ for an applied voltage of $2.5 \mathrm{~V}$, with a corresponding maximum and average temperature change on the actuator of $425{ }^{\circ} \mathrm{C}$ and $310^{\circ} \mathrm{C}$, respectively.

\section{FABRICATION}

The silicon-polymer laterally stacked electrothermal forward actuator is fabricated by using a three-mask process. The process flow is schematically shown in Fig. 3.

The actuators are fabricated by using 100-mm-diameter $527-\mu$ m-thick SOI wafers (p-type, 100 orientation), with a $400-\mathrm{nm}$-thick silicon buried oxide layer and a 30- $\mu \mathrm{m}$-thick p-type top silicon layer. A 300-nm-thick low-pressure chemical vapor deposition silicon nitride is deposited on both sides of the wafer. It serves as an electrical insulator on the front and on the backside as a mask during silicon substrate etching in $\mathrm{KOH}$ [see Fig. 3(a)]. A 600-nm-thick aluminum layer is deposited and patterned [Fig. 3(b)] to form the heater. The top silicon layer is subsequently etched by deep reactive ion etching (DRIE) to define the silicon frame [Fig. 3(c)]. Due to the characteristics of the DRIE, the etch rate is faster in larger windows than in smaller ones. Therefore, the use of SOI wafers is preferred as it guarantees (depth) uniformity of all etched structures.

As a polymer, we have considered the NANO SU8 2000 (Microchem, Inc.), which is a high contrast, negative, and epoxy-based line of conventional near-ultraviolet (350$400 \mathrm{~nm}$ ) radiation sensitivity photoresist with suitable chemical and mechanical properties [9]. SU8 allows the fabrication of structures with high aspect ratios and straight sidewalls [10]. It is a photopatternable polymer with a large coefficient of thermal expansion $\left(52-150 \mathrm{ppm} /{ }^{\circ} \mathrm{C}\right)$ [11], [12]. SU8 is a soft material compared with other conventional materials used in microtechnology. The Young's modulus of elasticity ranges from 3.2 to $4.4 \mathrm{GPa}$ [11], [12], which is about 40 times softer than silicon [13]. The negative photosensitive SU8-2002 with a viscosity of $7.5 \mathrm{cSt}$ is specifically developed to produce thin $(2-3 \mu \mathrm{m})$ films [14]. This polymer proved to be suitable for filling the 3- $\mu \mathrm{m}$-wide trenches present in our silicon-polymer electrothermal in-plane actuator. 


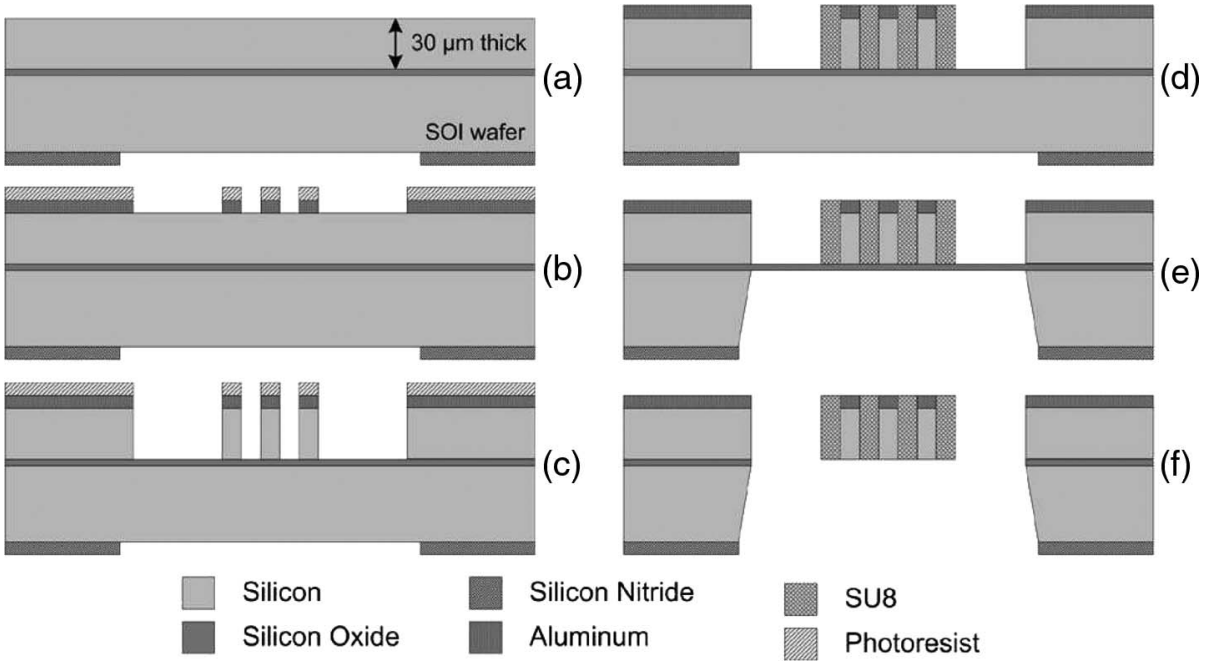

Fig. 3. Schematic view of the silicon-polymer laterally stacked microactuator fabrication process.
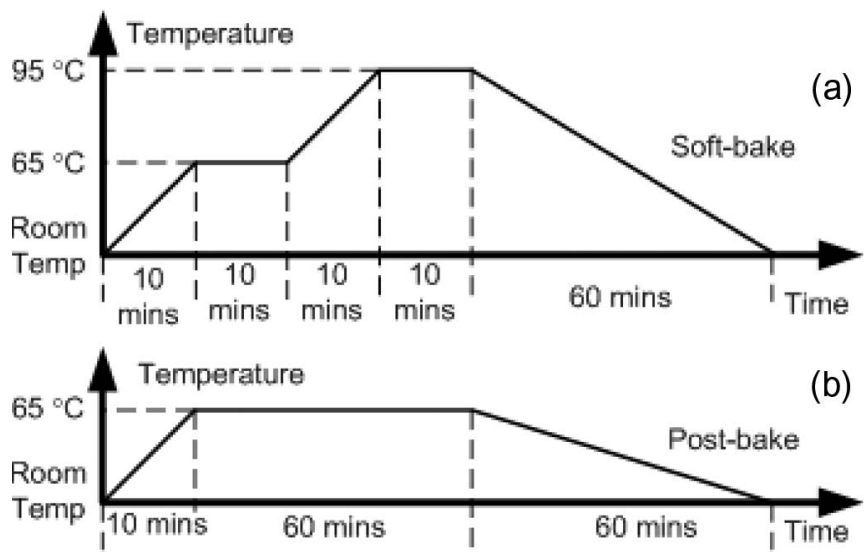

Fig. 4. Experimental procedure for soft bake and postbake of the SU8-2002 polymer.

The physical properties of SU8, like most polymers, are largely dependent on the type of structure to be realized and the fabrication process employed. In order to get a uniform and void-free filling of the narrow trenches, a modified coating and a carefully determined baking process are developed.

First, the wafer is treated in Hexamethyldisilazane (HDMS) for $5 \mathrm{~min}$ to improve the wetting behavior of the polymer. Then, a sufficient amount of SU8 2002 polymer to cover the entire wafer surface is applied on the substrate, and after waiting for 5 min to allow the polymer to sink into the trenches, the wafer is spun at $300 \mathrm{r} / \mathrm{min}$ for $30 \mathrm{~s}$. The samples are then soft-baked on a hot plate. The hot plate is ramped with a constant rate of $240{ }^{\circ} \mathrm{C} / \mathrm{h}$ from room temperature to $65^{\circ} \mathrm{C}$ and $95^{\circ} \mathrm{C}$ and then cooled at a constant rate to room temperature $(60 \mathrm{~min})$, as shown in Fig. 4(a).

Once the edge bead has been removed, the exposure is done by using a wavelength of $350 \mathrm{~nm}$ for $60 \mathrm{~s}$ in an EV240 contact aligner (EV Group Inc.). Postbake is performed after exposure on the same hot plate used for the soft bake, following the procedure shown in Fig. 4(b). The postbake procedure is followed by a relaxation step at room temperature for $30 \mathrm{~min}$. The resist is developed in SU8 developer for $10 \mathrm{~min}$ without mechanical oscillation aids to prevent deformation or debonding during

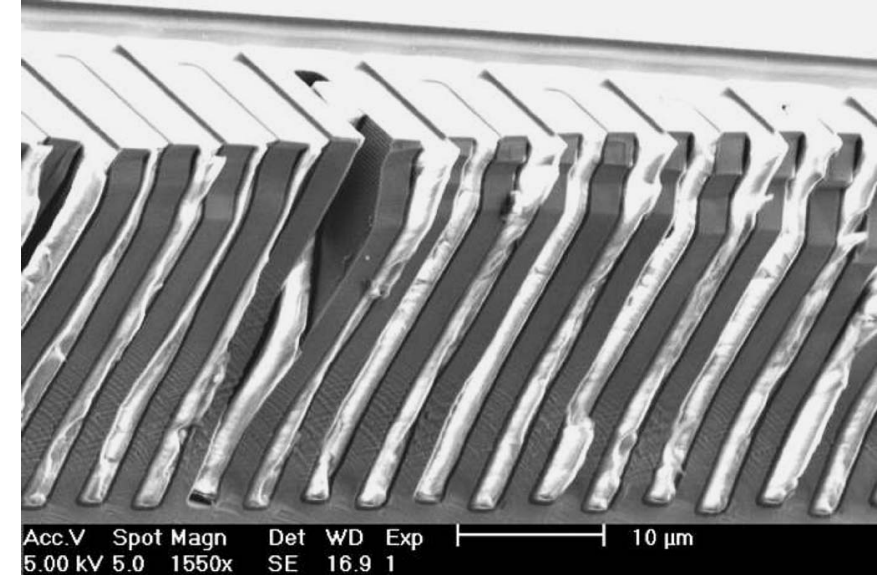

Fig. 5. SEM pictures of the void-free filling SU8-2002.

development [see Fig. 3(d)]. Fig. 5 shows SEM pictures of the void-free polymer-filled trenches.

Finally, the bulk silicon is etched from the backside in a 33 -wt $\% \mathrm{KOH}$ solution at $85^{\circ} \mathrm{C}$ until the buried oxide layer is reached [see Fig. 3(e)]. The front side of the wafer is protected during the etching in $\mathrm{KOH}$ by a vacuum holder. The last step is the release of the structure by dry etching the buried oxide layer from the backside [see Fig. 3(f)].

\section{Measurement Setups}

There are two methods for inducing a temperature change in this electrothermal microactuator: applying a current through the self-contained metal heater or using an external heat source.

In order to characterize the microactuator, a dc voltage is applied by using an HP4155A semiconductor parameter analyzer (Agilent Technologies, Inc.). The voltage is ramped from 0 to $2.5 \mathrm{~V}$. The displacement is monitored through the chargecoupled-device camera on top of the probe station.

The static displacement of the microactuator at any actuating voltage is then obtained by enlarging the picture and comparing it with the picture of the initial position. The external mechanical vibration causes a blur on the static picture which 


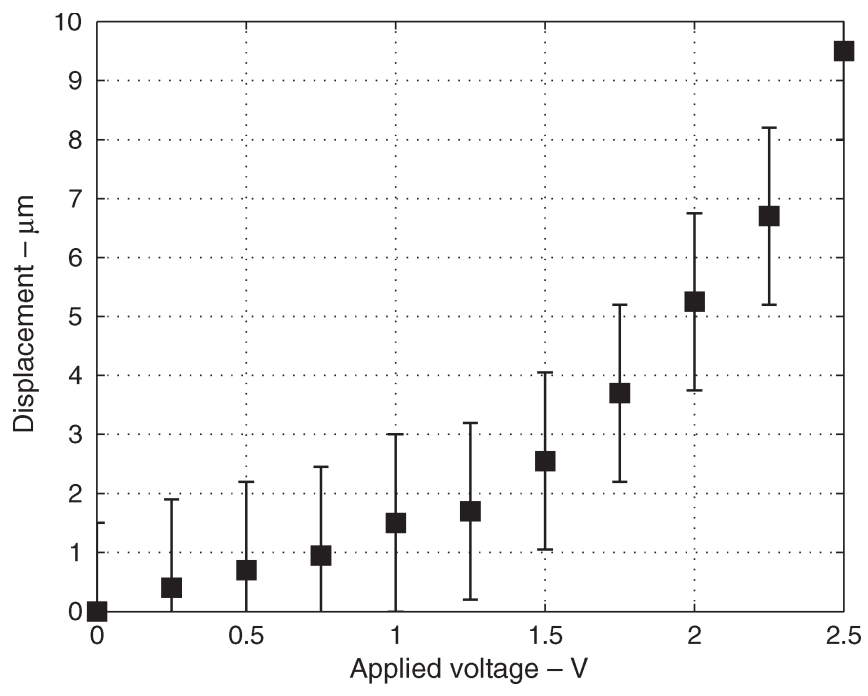

Fig. 6. Forward actuator movement in air versus the applied voltage.

determines the inaccuracy of the measurement. This inaccuracy is about $\pm 1.5 \mu \mathrm{m}$.

In addition, the thermal characteristic of the microactuator is also investigated by using the built-in external heat source of the Cascade probe station (Cascade Microtech, Inc.). The investigated temperature range is from $20{ }^{\circ} \mathrm{C}$ to $200{ }^{\circ} \mathrm{C}$ (the highest temperature of this measurement system) with a $20-{ }^{\circ} \mathrm{C}$ step and an accuracy of $\pm 0.1^{\circ} \mathrm{C}$. In order to get a stable temperature on the device, the measurement is performed $5 \mathrm{~min}$ after the chuck temperature has reached the setting point to allow sufficient stabilization. This externally supplied thermal energy causes expansion in the constrained polymer layer and the resulting actuation.

\section{EXPERIMENTAL RESULTS}

Fig. 6 shows the forward actuator movement versus the applied voltage. A movement up to $9.5 \mu \mathrm{m}$ at $2.5 \mathrm{~V}$ is measured. The measured results meet the simulated one within about $8 \%$ (see Table II).

Table II indicates the simulated and measured results of the in-plane forward actuator.

The average working temperature of the forward actuator can be estimated by monitoring the resistance change of the aluminum heater. The average increase in temperature of the forward actuator is given by

$$
\Delta T=T-T_{0}=\frac{R_{T}-R_{T_{0}}}{R_{T_{0}}} \frac{1}{\lambda_{\mathrm{Al}}}
$$

where $T_{0}$ is the room temperature $\left(20^{\circ} \mathrm{C}\right), \lambda_{\mathrm{Al}}=4.13 \times 10^{-3}$ [15] is the temperature coefficient of resistance of the aluminum film, and $R_{T_{0}}=88 \Omega$ and $R_{T}$ are the resistances of the aluminum heater at room temperature and at the investigated points, respectively.

Fig. 7 shows the measured resistance of the heater in air. The maximum resistance change for the full range of applied voltage is $103 \%$. The average working temperature of the forward actuator can be calculated from the resistance change by using (1). The average temperature change is $250{ }^{\circ} \mathrm{C}$ when the applied voltage is $2.5 \mathrm{~V}$. The maximum working temperature on the actuator can be estimated to be about $356{ }^{\circ} \mathrm{C}$, considering the simulated and measured average temperatures reported in Table II and in [4]. The measured temperature results meet the simulated ones within about $19 \%$. The difference could be explained as due to the different heat conduction and convection conditions between experiments and simulation and the assumption of the temperature-independent physical parameters of the employed materials. Fig. 8 shows the displacement of the forward actuator versus the average temperature change on the actuator.

Instead of electrical activation, external heat is applied on the wafer with the same probe station used for the electrical actuation measurement. The static displacement of the forward actuator is also measured under an optical microscope. The mechanical vibration of the chuck increases when activating the chuck temperature controller due to the heat flow under the chuck. Therefore, the measurement error is somewhat larger (about $\pm 2 \mu \mathrm{m}$ ) in this case.

The displacement of the forward actuator due to the external heat is also shown in Fig. 8. These values meet the electrical actuation values within $5 \%$ for the average working temperature range of $20{ }^{\circ} \mathrm{C}-200{ }^{\circ} \mathrm{C}$. It indicates that the aluminum deposition process behaves as expected and that the average working temperature of the actuator can be well estimated from the resistance change of the aluminum heater.

The physical properties of the polymer material, such as the volume coefficient of expansion, Young's modulus, and so on, are greatly changed in pseudosecond order at the glass transition temperature $T_{\mathrm{g}}$ where the material properties change from the glassy region to the rubbery plateau region [16]. The glass transition temperature of the polymer itself varies widely with the fabrication process, structure, and other parameters [12], [16], [17]. Reference [12] shows that the $T_{\mathrm{g}}$ of SU8 is nearly the baking temperature when it is below $220{ }^{\circ} \mathrm{C}$ for a baking time of $20 \mathrm{~min}$. However, the $T_{\mathrm{g}}$ can increase gradually up to the "steady-state" temperature of $118^{\circ} \mathrm{C}$ when the material is baked for a longer time $(60 \mathrm{~min})$ at a constant temperature of $95{ }^{\circ} \mathrm{C}$. The cross point of the two linear fitted lines of the external heat measured results for the temperature ranges lower and higher than $120^{\circ} \mathrm{C}$, respectively, shows the transition temperature $T_{\mathrm{g}}$ of the employed SU8 polymer (see Fig. 8). The estimated glass transition of the SU8 of $120{ }^{\circ} \mathrm{C}$ is quite close to the value of $118{ }^{\circ} \mathrm{C}$ reported in [12]. It may indicate that the proposed postbake process of this device is sufficient to get the steady-state value of the glass transition temperature.

More information about the glass transition temperature and other physical characteristics of the polymer can be found in the glass-rubber transition behavior chapter in [16].

The transition temperature $T_{\mathrm{g}}$ shows that this proposed device works on both the glassy and rubbery plateau regions. It therefore may partly explain the nonlinear characteristic of the displacements due to the working temperature and also the power consumption.

The power consumption is calculated through the applied voltage and the corresponding current. Fig. 9 shows the 
TABLE II

Performance of the Electrothermal Forward ACTUATOR

\begin{tabular}{l|r|r|r}
\hline Parameters & Simulated results & Measured results & Unit \\
\hline Forward actuator displacement at $2.5 \mathrm{~V}$ & 8.1 & 9.8 & $\mu \mathrm{m}$ \\
Forward actuator power consumption at $2.5 \mathrm{~V}$ & 38 & 35 & $\mathrm{~mW}$ \\
Forward actuator average temperature change at $2.5 \mathrm{~V}$ & 310 & 250 & ${ }^{\circ} \mathrm{C}$ \\
Forward actuator maximum temperature change at $2.5 \mathrm{~V}$ & 425 & - & ${ }^{\circ} \mathrm{C}$ \\
Aluminum heater resistance at room temperature $\left(20^{\circ} \mathrm{C}\right)$ & - & 88 & $\Omega$ \\
Aluminum heater resistance at $2.5 \mathrm{~V}$ & - & 179 & $\Omega$ \\
Thermal response time on heating step $(0.25$ to $2.5 \mathrm{~V})$ & - & 40 & $\mathrm{~ms}$ \\
Thermal response time on cooling step $(2.5$ to $0.25 \mathrm{~V})$ & - & 50 & $\mathrm{~ms}$ \\
Estimated bandwidth frequency & - & 11 & $\mathrm{~Hz}$ \\
\hline
\end{tabular}

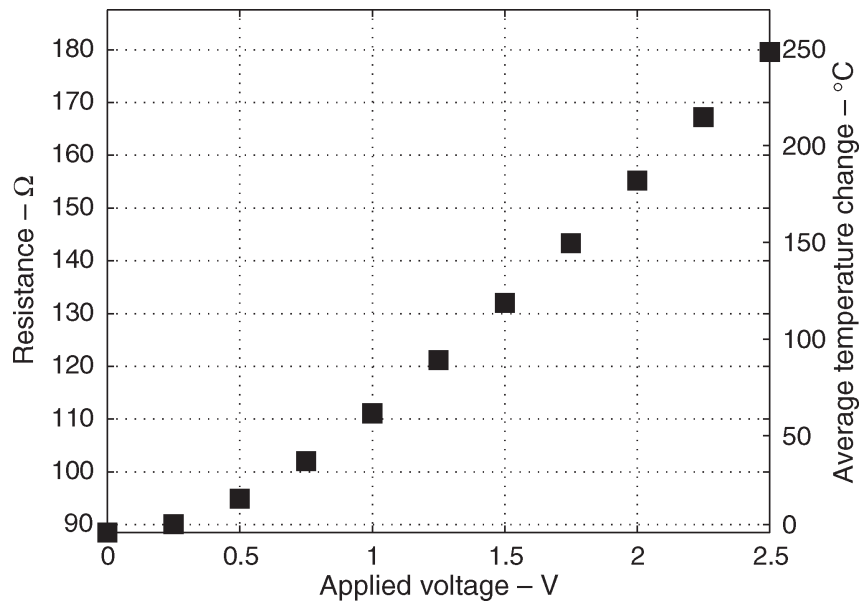

Fig. 7. Resistance of the heater versus applied voltage and the resulting average temperature change in the microactuator.

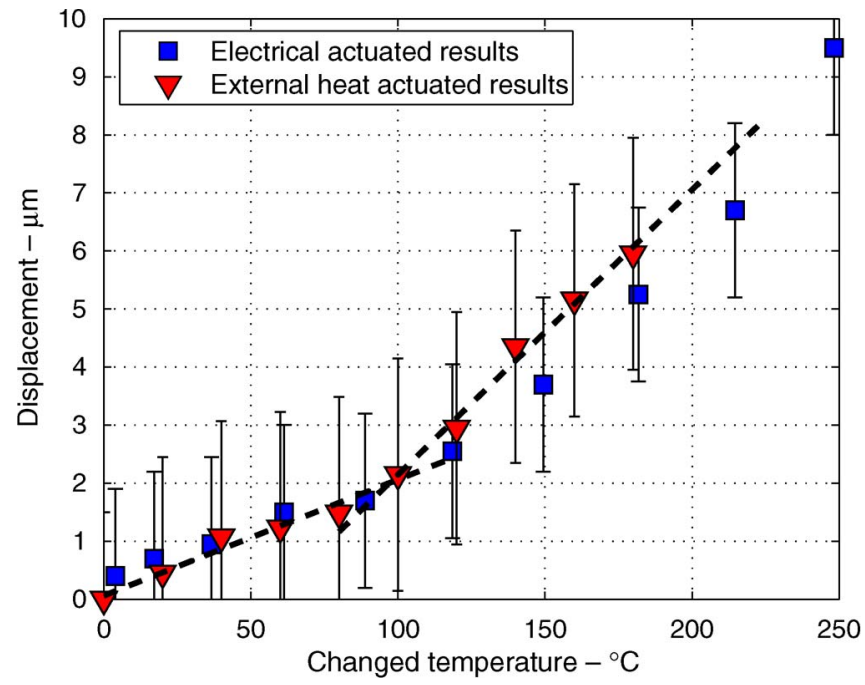

Fig. 8. Forward actuator movement in air versus the average temperature change.

forward actuator movement versus the power consumption of the forward actuator. The average power consumption is about $3.7 \mathrm{~mW}$ for a $1-\mu \mathrm{m}$ movement of the forward actuator.

The response time of the presented forward actuator is estimated from the thermal time response. The thermal time response of the forward actuator operating in air is obtained by investigating the time-resolved electrical measurement of

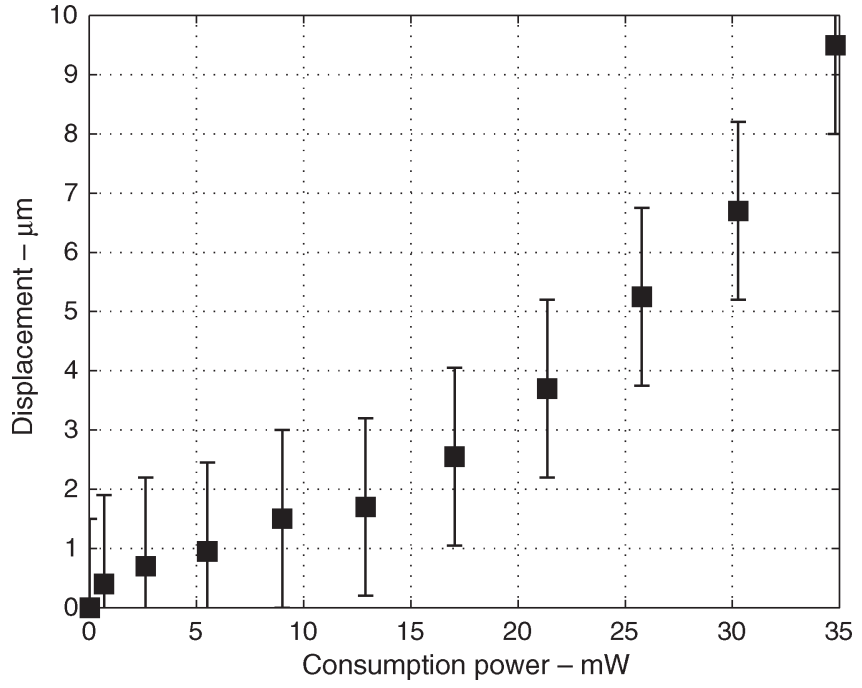

Fig. 9. Forward actuator movement versus the power consumption.

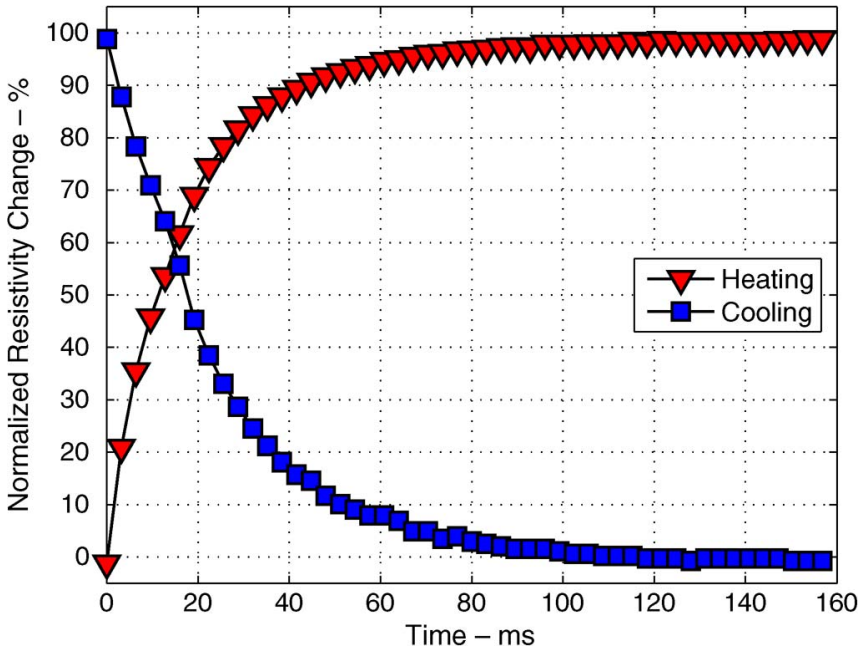

Fig. 10. Time-resolved electrical resistance of the forward actuator in air.

the aluminum heater (see Fig. 10). A single-step voltage of $0.25-2.5 \mathrm{~V}$ and $2.5-0.25 \mathrm{~V}$ is applied to the actuator to characterize the heating and cooling response time, respectively. The drive voltage of $2.5 \mathrm{~V}$ corresponds to the maximum displacement of the forward actuator. Fig. 10 shows the corresponding resistance due to the step input voltages. The actuators reach a $90 \%$ of full range steady state after approximately 


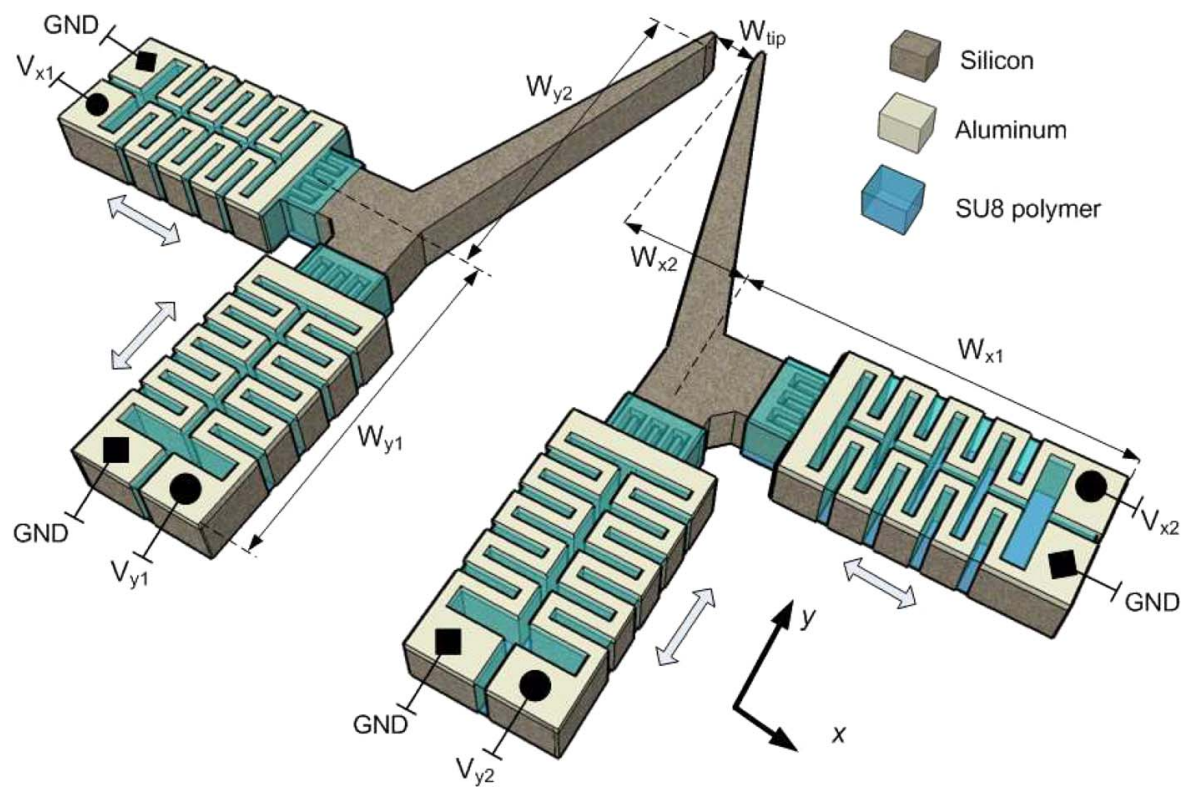

Fig. 11. 2-D microgripper based on four silicon-polymer laterally stacked in-plane forward actuators.

TABLE III

GEOMETRY OF THE ElECTROTHERMAL 2-D MicRogRIPPER

\begin{tabular}{l|l|r|r}
\hline Parameters & Symbol & Value & Unit \\
\hline Geometry of gripper along $x$-axis & $W_{x 1}$ & 365 & $\mu \mathrm{m}$ \\
Geometry of gripper along $x$-axis & $W_{x 2}$ & 120 & $\mu \mathrm{m}$ \\
Geometry of gripper along $y$-axis & $W_{y 1}$ & 365 & $\mu \mathrm{m}$ \\
Geometry of gripper along $y$-axis & $W_{y 2}$ & 375 & $\mu \mathrm{m}$ \\
Initial gap between two jaws & $W_{t i p}$ & 40 & $\mu \mathrm{m}$ \\
\hline
\end{tabular}

40 and $50 \mathrm{~ms}$ for heating and cooling, respectively. An $\sim 11-\mathrm{Hz}$ bandwidth frequency of this actuator is therefore calculated.

\section{TWO-DIMENSIONAL MICROGRIPPER}

A very interesting application that largely benefits from the specific characteristics of these actuators is a novel 2-D siliconpolymer laterally stacked electrothermal microgripper.

\section{A. Design}

The design and geometry of the microgripper is shown in Fig. 11 and Table III. The microgripper's arm structure consists of two perpendicular forward actuators to control the motion along the $x$ - and $y$-axes, respectively. To control this 2-D microactuator, four input voltages are employed, as shown in Fig. 11. The moving mechanism is shown in Fig. 12.

When voltages $V_{x 1}$ and $V_{x 2}$ are applied on the two $x$ actuators, the microgripper closes along the $x$-axis to clamp the object (phase 1 in Fig. 12). The displacement in the $x$-direction $u_{x}$ of each jaw is given by

$$
u_{x}=\frac{W_{y 1}+W_{y 2}}{W_{y 1}} d
$$

where $W_{y 1}$ and $W_{y 2}$ are related to the dimensions of the actuator and the gripper arm on the $y$-axis, and $d$ is the displacement of the forward actuator.

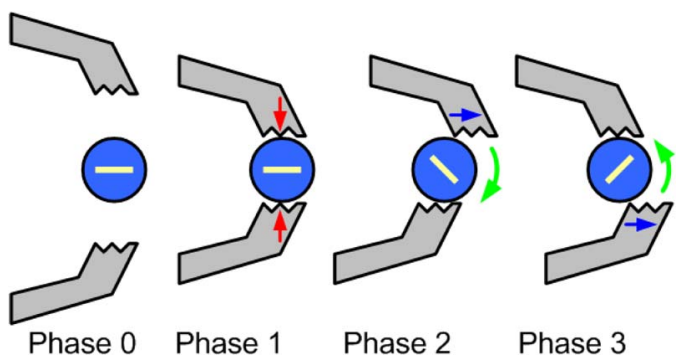

Fig. 12. Schematic drawing of the 2-D microgripper movement mechanism. Phase 0 is the initial position. Phase 1: Jaws are closed on the $y$-axis to clamp an object. Phase 2: One jaw is moved along the $x$-axis to rotate the object clockwise. Phase 3: The other jaw is moved along the $x$-axis to rotate the object counterclockwise.

When voltages $V_{y 1}$ and $V_{y 2}$ are applied on the two $y$ actuators, the microgripper is stretched along the $y$-axis (phase 2 or 3 in Fig. 12). The displacement $u_{y}$ is thus given by

$$
u_{y}=\frac{W_{x 1}+W_{x 2}}{W_{x 1}} d
$$

where $W_{x 1}$ and $W_{x 2}$ are related to the dimensions of the actuator and the gripper arm on the $x$-axis.

By combining the motion in two directions, this 2-D microgripper provides the additional feature to rotate the clamped object clockwise and counterclockwise (phases 2 and 3 in Fig. 12) when a voltage is alternately applied on the $y$ actuators. An object with a radius $r$ can be rotated of an angle (with respect to its center) $\alpha$ calculated as

$$
\alpha=\frac{1}{2} \frac{u_{y}}{2 \pi r} 360^{\circ} .
$$

\section{B. Experimental Results}

Fig. 13 shows the realized silicon-polymer laterally stacked electrothermal 2-D microgripper. The parameters related to the 

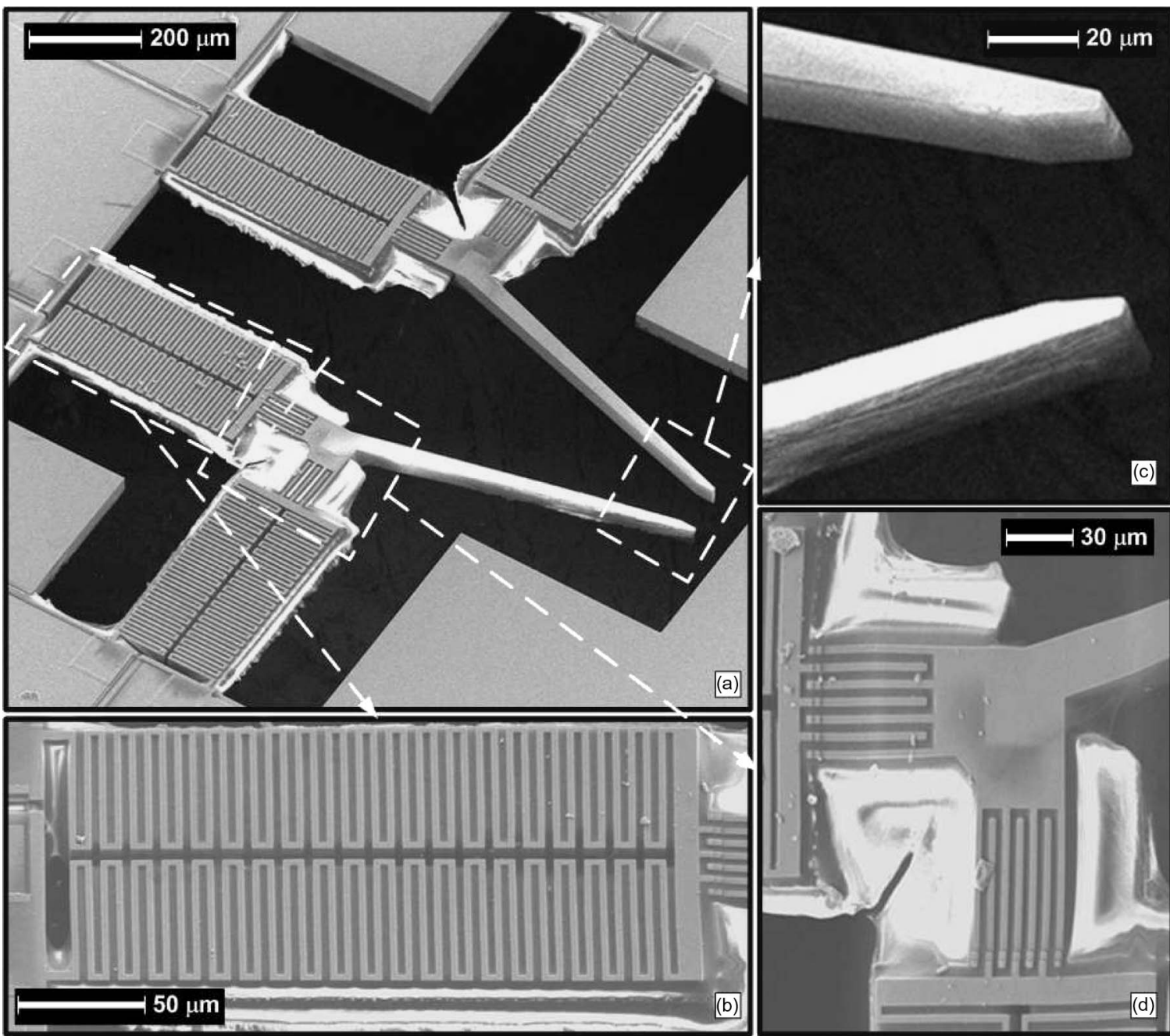

Fig. 13. SEM pictures of the fabricated 2-D microgripper. (a) Entire device. (b) Front view of the electrothermal forward actuator. (c) Microgripper jaws. (d) Two forward actuators are connected together by using silicon comb structure filled with the SU8.
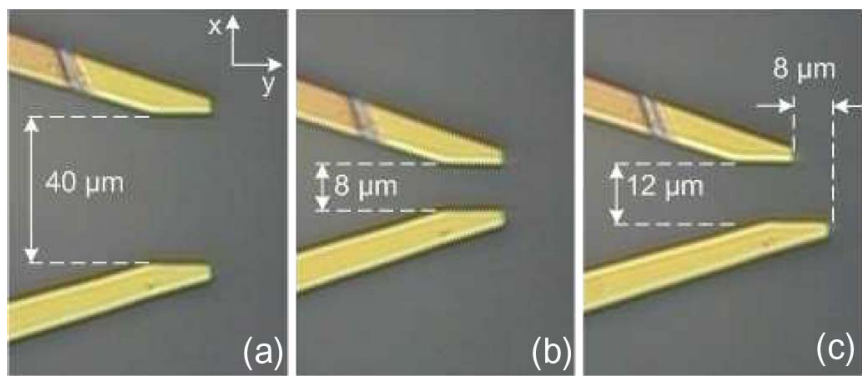

Fig. 14. Two-dimensional microgripper operation. (a) Initial position: the distance between the two jaws is $40 \mu \mathrm{m}$ on the $x$-axis. (b) The microgripper jaws when applying $2.5 \mathrm{~V}$ to both $y$ actuators. (c) One jaw moves along the $y$-axis when applying $2.5 \mathrm{~V}$ to its $y$ actuator.

geometry of the fabricated microgripper are reported in Tables I and III and Figs. 2 and 11.

Fig. 14 shows images of some typical states of the 2-D microgripper. Fig. 14(a) shows the initial position of the 2-D microgripper jaws. The gap between the two jaws is $40 \mu \mathrm{m}$.

In Table IV, the simulated and measured results of the 2-D microgripper are reported.

Fig. 15 shows the movement of a single jaw of the microgripper along the $x$ - and $y$-axes versus the applied voltage. The
TABLE IV

Performance of the Electrothermal 2-D Microgripper

\begin{tabular}{l|r|r}
\hline Parameters & Value & Unit \\
\hline Measured gripper displacement along $x$-axis at 2.5 V & 17 & $\mu \mathrm{m}$ \\
Measured gripper displacement along $y$-axis at 2.5 V & 11 & $\mu \mathrm{m}$ \\
Simulated gripper stiffness along $x$-axis & 11.4 & $\mathrm{~N} / \mathrm{m}$ \\
Simulated gripper stiffness along $y$-axis & 74 & $\mathrm{~N} / \mathrm{m}$ \\
Maximum generated force on $x$-axis & 196 & $\mu \mathrm{N}$ \\
Maximum generated force on $y$-axis & 814 & $\mu \mathrm{N}$
\end{tabular}

maximum measured movements of one jaw are 17 and $11 \mu \mathrm{m}$ along the $x$ - and $y$-axes, respectively. Hence, this microgripper is capable of manipulating an object with a diameter of 6-40 $\mu \mathrm{m}$. The difference between the movement of the jaw along the $x$ - and $y$-axes is related to the geometry of the design, as indicated in (2) and (3). The maximum angle of rotation can be estimated based on (4) and the related measured values. For a $30-\mu \mathrm{m}$-diameter object, this angle is $21^{\circ}$ both clockwise and counterclockwise. The applied force on the clamped object can be estimated through the measured displacement and the simulated stiffness of the gripper arm. This proposed device 


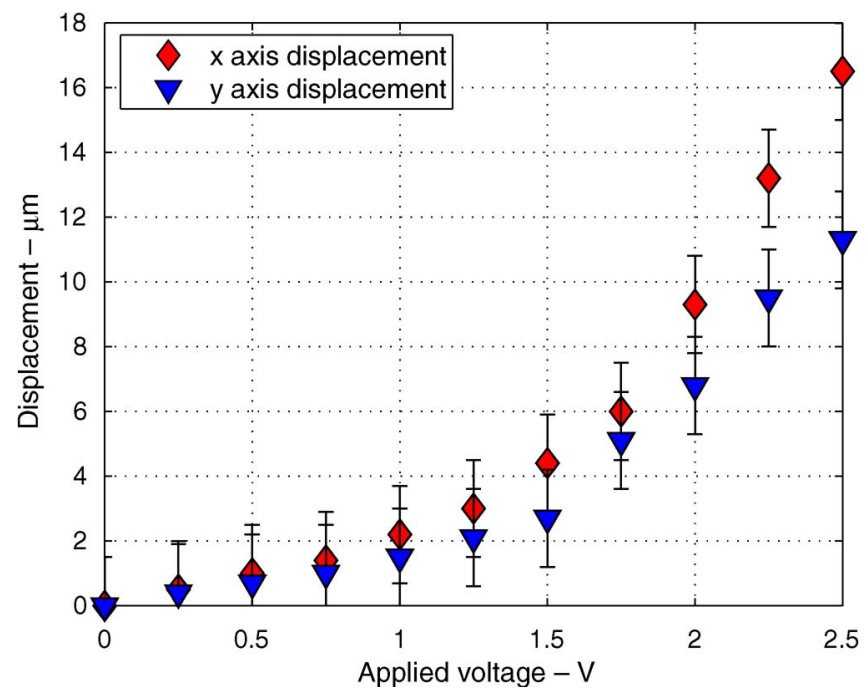

Fig. 15. Microgripper jaw movement in air along the $x$ - and $y$-axes versus applied voltage.

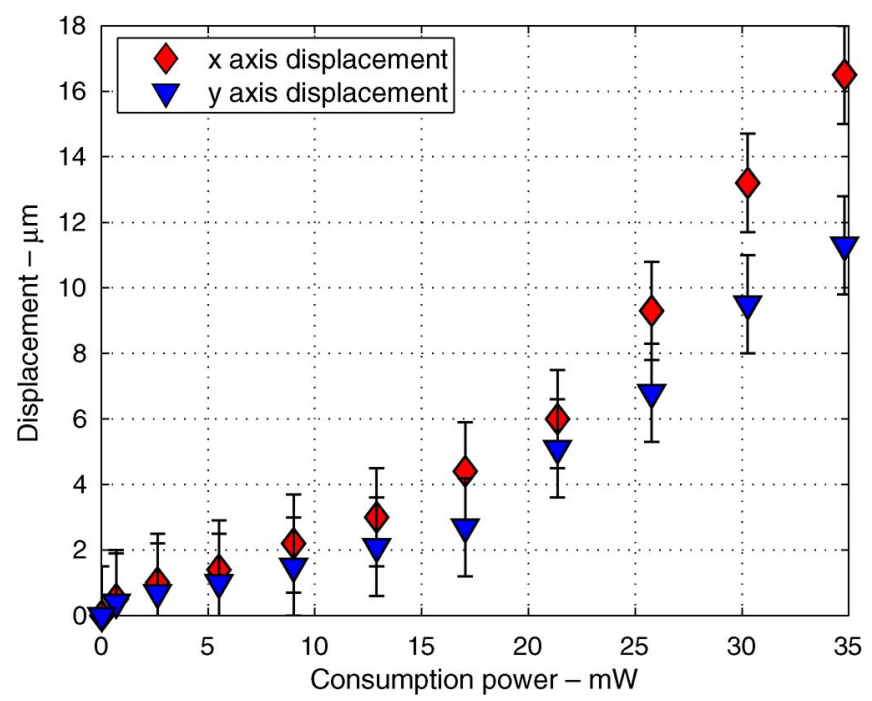

Fig. 16. Microgripper jaw movement in air along the $x$ - and $y$-axes versus power consumption

is capable of generating a maximum applied force of 196 and $814 \mu \mathrm{N}$ on the $x$ - and $y$-axes, respectively (see Table IV).

Fig. 16 shows the microgripper jaw displacement along the $x$ - and $y$-axes versus the power consumption. For $1-\mu \mathrm{m}$ microgripper jaw movement along the $x$ - and $y$-axes, about 2.1 and $3.1 \mathrm{~mW}$ are consumed, respectively. The difference is due to the geometry of the gripper jaws (see Fig. 11) and is expressed in (2) and (3). The main failure mechanism observed during testing the microgripper is the appearance of cracks in the aluminum heater and the silicon meandering structure when the applied voltage is increased to about $3 \mathrm{~V}$ and the working temperature of the actuator is too high. There is no indication of loss of adhesion between the SU8 and the silicon plates even at these temperatures. This is probably due to the large interface between the meandering silicon structure and the polymer. To evaluate the lifetime of the microgripper, it is repeatedly actuated in air with a $2-\mathrm{V}$ amplitude (which generates $80 \%$ of its maximum displacement) and a frequency of $1.7 \mathrm{~Hz}$ for $12 \mathrm{~h}(70000 \mathrm{~Hz})$. The same reliability testing process is repeated after one week and then one month. No degradation in performance is observed so far.

\section{CONCLUSION}

A novel silicon-polymer electrothermal in-plane forward actuator with a large measured displacement (up to $9.5 \mu \mathrm{m}$ ) at the applied voltage of $2.5 \mathrm{~V}$ was presented. A 2-D electrothermal microgripper, which is an interesting application of the proposed forward actuator, was presented as well. Microgripper jaw displacements up to 17 and $11 \mu \mathrm{m}$ along the $x$ - and $y$-axes, respectively, at $2.5-\mathrm{V}$ applied voltage were measured. The microgripper can be used to grasp and rotate an object with a diameter of 6-40 $\mu \mathrm{m}$. For a $30-\mu \mathrm{m}$-diameter object, a maximum rotation of about $21^{\circ}$ both clockwise and counterclockwise can be performed. The maximum average temperature change is $250{ }^{\circ} \mathrm{C}$ at $2.5 \mathrm{~V}$. The proposed device works at both the glassy and rubbery plateau regions of the SU8 polymer. The average power consumptions are about 2.1 and $3.1 \mathrm{~mW}$ for a $1-\mu \mathrm{m}$ movement along the $x$ - and $y$ axes, respectively. The bandwidth frequency at the full range displacement is calculated to be $11 \mathrm{~Hz}$. The fabrication process is based on conventional bulk micromachining and polymer filling, and it is CMOS-compatible. The proposed microgripper due to the demonstrated features appears to be quite suitable for microobject manipulation, device positioning, microrobotics, and microassembly.

\section{ACKNOWLEDGMENT}

The authors would like to thank the DIMES-IC Processing Group for the technical support and P. J. F. Swart for his assistance with the electronic measurements. The authors would also like to thank J. Wei, Dr. H. W. van Zeijl, Dr. J. F. Creemer, Dr. J. F. L. Goosen, and F. van Keulen for the numerous discussions.

\section{REFERENCES}

[1] N. Chronis and L. P. Lee, "Electrothermally activated SU-8 microgripper for single cell manipulation in solution," J. Microelectromech. Syst., vol. 14, no. 4, pp. 857-863, Aug. 2005.

[2] N.-T. Nguyen, S.-S. Ho, and C. L.-N. Low, "A polymeric microgripper with integrated thermal actuators," J. Micromech. Microeng., vol. 14, no. 7, pp. 969-974, May 2004.

[3] J. W. L. Zhou, H.-Y. Chan, T. K. H. To, K. W. C. Lai, and W. J. Li, "Polymer MEMS actuators for underwater micromanipulation," IEEE/ASME Trans. Mechatronics, vol. 9, no. 2, pp. 334-342, Jun. 2004.

[4] G.-K. Lau, J. F. L. Goosen, F. van Keulen, T. Chu Duc, and P. M. Sarro, "Polymeric thermal microactuator with embedded silicon skeleton: Part I-Design and analysis," J. Microelectromech. Syst., vol. 17, no. 4, pp. 809-822, Aug. 2008.

[5] T. Chu Duc, G. K. Lau, J. Wei, and P. M. Sarro, " 2 D electro-thermal microgrippers with large clamping and rotation motion at low driving voltage," in Proc. 20th IEEE Conf. MEMS, 2007, pp. 687-690.

[6] T. Chu Duc, G. K. Lau, and P. M. Sarro, "Polymer constraint effect for electrothermal bimorph microactuators," Appl. Phys. Lett., vol. 91, no. 10, pp. 101 902-1-101902-3, Sep. 2007.

[7] P. K. Wong, U. Ulmanella, and C.-M. Ho, "Fabrication process of microsurgical tools for single-cell trapping and intracytoplasmic injection," J. Microelectromech. Syst., vol. 13, no. 6, pp. 940-946, Dec. 2004. 
[8] M. Mita, H. Kawara, H. Toshiyoshi, M. Ataka, and H. Fujita, "An electrostatic 2-dimensional micro-gripper for nano structure," in Proc. 12th IEEE Int. Conf. Solid-State Sens., Actuators, Microsyst., Jun. 8-12, 2003, pp. 272-275.

[9] A. Mata, A. J. Fleischman, and S. Roy, "Fabrication of multi-layer SU-8 microstructures," J. Micromech. Microeng., vol. 16, no. 2, pp. 276-284, Jan. 2006

[10] J. D. Williams and W. Wang, "Study on the postbaking process and the effects on UV lithography of high aspect ratio SU-8 microstructures," J. Microlithogr. Microfabr. Microsyst., vol. 3, no. 4, pp. 563-568, Oct. 2004.

[11] H. Lorenz, M. Laudon, and P. Renaud, "Mechanical characterization of a new high-aspect-ratio near UV-photoresist," Microelectron. Eng., vol. 41/42, pp. 371-374, Mar. 1998.

[12] R. Feng and R. J. Farris, "Influence of processing conditions on the thermal and mechanical properties of SU8 negative photoresist coatings," J. Micromech. Microeng., vol. 13, no. 1, pp. 80-88, Dec. 2003.

[13] J. J. Wortman and R. A. Evans, "Young's modulus, shear modulus, and Poisson's ratio in silicon and germanium," J. Appl. Phys., vol. 36, no. 1, pp. 153-156, Jan. 1965.

[14] NANO SU-8 2000 Negative Tone Photoresist Formulations 2002-2025, MicroChem Corp., Newton, MA, 2002.

[15] Handbook of Thermophysical Properties of Metals at High Temperatures, Nova, Commack, NY, 1996, pp. 139-144.

[16] L. H. Sperling, Introduction to Physical Polymer Science. Hoboken, NJ: Wiley, 2006

[17] J. H. van Zanten, W. E. Wallace, and W. Wu, "Effect of strongly favorable substrate interactions on the thermal properties of ultrathin polymer films," Phys. Rev. E, Stat. Phys. Plasmas Fluids Relat. Interdiscip. Top., vol. 53, no. 3, pp. R2053-R2056, Mar. 1996.

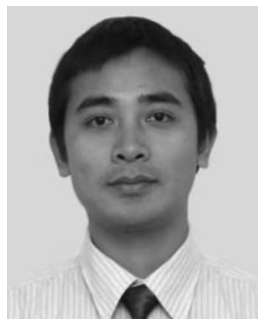

Trinh Chu Duc received the B.S. degree in physics from Hanoi University of Science, Hanoi, Vietnam, in 1998, the M.Sc. degree in electrical engineering from Vietnam National University, Hanoi, in 2002, and the Ph.D. degree from Delft University of Technology, Delft, The Netherlands, in 2007. His Ph.D. research topics are piezoresistive sensors, polymeric actuators, sensing microgripper for microparticle handling, and microsystems technology.

$\mathrm{He}$ is currently an Assistant Professor with the Faculty of Electronics and Telecommunication, College of Technology, Vietnam National University.

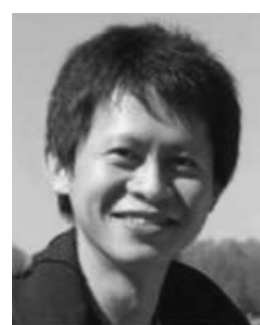

Gih-Keong Lau received the bachelor's (with firstclass honors) and master's degrees in mechanical engineering from Nanyang Technological University (NTU), Singapore, in 1998 and 2001, respectively, and the Ph.D. degree from Delft University of Technology, Delft, The Netherlands, in 2007. His Ph.D. research topics were polymeric actuators, electroactive polymer, microfabrication, and multiphysics modeling and design.

From 2001 to 2003, he was a Research Associate with the Center for Mechanics of Microsystems, NTU, working on the topics of topology optimization of compliant mechanisms, mechanical design for hard disk drives, and piezoelectric actuators. He is currently an Assistant Professor with the School of Mechanical and Aerospace Engineering, NTU.

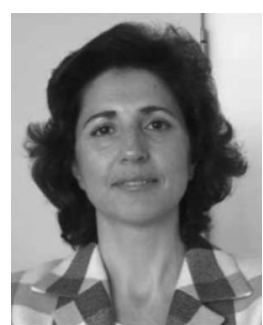

Pasqualina M. Sarro (M'84-SM'97-F'07) received the Laurea degree (cum laude) in solid-state physics from the University of Naples, Naples, Italy, in 1980 and the Ph.D. degree in electrical engineering from Delft University of Technology, Delft, The Netherlands, in 1987. Her Ph.D. dissertation dealt with infrared sensors based on integrated silicon thermopiles.

From 1981 to 1983 , she was a Postdoctoral Fellow with the Photovoltaic Research Group, Division of Engineering, Brown University, RI, where she worked on thin-film photovoltaic cell fabrication by chemical spray pyrolysis. Since then, she has been with the Delft Institute of Microelectronics and Submicron Technology (DIMES), Delft University of Technology, where she is responsible for the research on integrated silicon sensors and MEMS technology. In April 1996, she became an Associate Professor, and in December 2001 a Full Professor, in the Electronic Components, Materials and Technology Laboratory, Delft Institute of Microsystems and Nanoelectronics, Delft University of Technology. She has authored and coauthored more than 300 journal and conference papers.

Dr. Sarro received the EUROSENSORS Fellow Award for her contribution to the field of sensor technology in 2004. She has served as a Member of the Technical Program Committees of the European Solid-State Device Research Conference (since 1995), the EUROSENSORS Conference (since 1999), and the IEEE International Conference on Micro Electro Mechanical Systems (2006 and 2007). Further, she was Technical Program Cochair for the First IEEE Sensors Conference (2002) and the Technical Program Chair for the Second and Third IEEE Sensors Conference (2003 and 2004). She is also a member of the AdCom of the IEEE Sensor Council. 